Ethos (Jurnal Penelitian dan Pengabdian Masyarakat): 232-239

\title{
Penerapan Open Education Pada Sekolah Menengah Pertama Islam TerPadu TARUNA INSANI BOARDING SCHOOL
}

\section{IMPLEMENTATION OF OPEN EDUCATION AT ISLAMIC INTEGRATED JUNIOR HIGH SCHOOL TARUNA INSANI BOARDING SCHOOL}

\author{
${ }^{1}$ Theresiawati, ${ }^{2}$ Henki Bayu Seta, dan ${ }^{3}$ Jayanta \\ ${ }^{1,2,3}$ DIII Sistem Informasi Jurusan S1 Teknik Informatika, Universitas Pembangunan Nasional Veteran \\ Jakarta,Jl. RS. Fatmawati, Jakarta Selatan 12450 \\ e-mail: ${ }^{1}$ theresiawati@upnvj.ac.id, ${ }^{2}$ henkibayu@upnvj.ac.id, ${ }^{3}$ anta.jayanta@gmail.com
}

\begin{abstract}
The main problems faced by Taruna Insani Boarding is how to keep the learning process done when the learners return to the family once a month. How SMPIT Taruna Insani can facilitate teachers and students to be able to exchange or share files associated with school materials or school activities, talk through discussion forums, conduct exams or daily tests and learners do upload assignments and teacher assessment directly via e-learning. The purpose of community service enhance the ability of learners and teachers to play an active role in understanding the learning material, improve the quality of the subject matter, provide ease of teachers to be able to monitor any learning content management material more attractive, assignments and assessment tasks learners directly through based learning web (e-learning)so that the learning process will be paper less because the task is no longer done by printing tasks. The method used are analysis of the situation, identify solutions, planning activities, socialization, training for instructors and participants.
\end{abstract}

Keywords: Open education, e-learning, training

\begin{abstract}
Abstrak. Permasalahan utama yang dihadapi oleh pondok pesantren Taruna Insani adalah bagaimana cara yang harus dilakukan agar proses belajar mengajar tetap dapat dilakukan saat peserta didik kembali ke pihak keluarga sebulan sekali. Bagaimana SMPIT Taruna Insani dapat memfasilitasi pengajar dan murid untuk dapat bertukar atau berbagi file yang berhubungan dengan materi sekolah atau kegiatan sekolah, berdiskusi melalui forum diskusi, melakukan ujian atau ulangan harian dan peserta didik melakukan unggah tugas serta pengajar melakukan penilaian langsung melalui e-learning. Tujuan pengabdian masyarakat meningkatkan kemampuan peserta didik dan pengajar untuk berperan aktif dalam memahami materi pembelajaran, meningkatkan kualitas dari materi pelajaran, memberikan kemudahan pengajar untuk dapat melakukan monitoring pembelajaran seperti manajemen konten materi lebih menarik, pemberian tugas dan penilaian tugas peserta didik secara langsung melalui pembelajaran berbasis web (elearning) sehingga proses pembelajaran tersebut akan paper less karena tugas tidak lagi dilakukan dengan mencetak tugas. Metode yang digunakan analisis situasi, identifikasi solusi, penyusunan rencana kegiatan, sosialisasi, pelatihan unttuk para pengajar dan peserta ajar.
\end{abstract}

Kata kunci: Open education, e-learning, pelatihan 


\section{Pendahuluan}

E-learning merupakan salah satu open education yang banyak diterapkan di lembaga pendidikan seperti (sekolah maupun Universitas). Berdasarkan angket awal yang telah dilakukan, SMPIT Taruna Insani Pesantren Tahfidz Modern 82\% responden menyatakan belum ada pembelajaran elearning berbasis web. $100 \%$ responden membutuhkan pembelajaran e-learning berbasis web agar dapat bertukar atau berbagi file yang berhubungan dengan materi sekolah atau kegiatan sekolah, berdiskusi melalui forum diskusi, melakukan ujian atau ulangan harian dan peserta didik melakukan unggah tugas serta pengajar melakukan penilaian langsung melalui e-learning.

Mencermati kebutuhan open education tersebut maka Fakultas Ilmu KomputerUPN "Veteran" Jakarta melalui kegiatan pengabdian kepada masyarakat memberikan pelatihan penggunaan perangkat lunak elearning untuk mendukung proses pembelajaran open education. Pelatihan dilakukan dengan menggunakan metode learning by doing, dimana setiap peserta dapat belajar dengan cara langsung mempraktekkan. Program pengabdian masyarakat ini menggunakan metode learning by doing, dan sosialisasi yang disertai latihan. Tujuan dari program Pengabdian Kepada Masyarakat (PKM) FIKUPNVJ ini adalah berupa artikel ilmiah serta pemanfaatan elearning untuk memudahkan proses pembelajaran antara pengajar dan peserta didik. Sehingga peserta didik akan lebih interaktif dan menarik dalam proses pembelajaran.

\section{Kajian Literatur}

Salah satu yang memfasilitasi open education yaitu dengan menggunakan fasilitas e-learning. E-Learning (pembelajaran secara elektronik), dengan konsep ini sistem belajar mengajar akan tidak terbatas ruang dan waktu. E-learning merupakan singkatan dari Elektronic Learning, merupakan cara baru dalam proses belajar mengajar yang menggunakan media elektronik khususnya internet sebagai sistem pembelajarannya. Seorang pengajar/pengajar dapat memberikan materi pelajaran dari mana saja. Begitu juga seorang peserta didik dapat mengikuti aktifitas pembelajaran dari mana saja. Untuk mendapatkan hasil yang efektif dan efisien, penyelenggaraan pengabdian masyarakat dilakukan secara terstruktur dan materi pelatihan dirumuskan sesuai dengan kebutuhan peserta baik peserta pengajar maupun para peserta didik santri. E-learning merupakan dasar dan konsekuensi logis dari perkembangan teknologi informasi dan komunikasi. Mencermati kebutuhan open education tersebut maka Fakultas Ilmu Komputer-UPN"Veteran" Jakarta melalui kegiatan pengabdian kepada masyarakat memberikan pelatihan penggunaan perangkat lunak e-learning untuk mendukung proses pembelajaran open education. Dengan adanya open education akan memudahkan pengajar dan peserta didik untuk melakukan proses pembelajar. Pengajar dan peserta didik akan mudah untuk upload / download content, memonitor pemberian tugas dan melakukan penilaian serta peserta didik akan dengan mudah mengunggah tugas. Sehingga proses pembelajaran tersebut akan paper less karena tugas tidak lagi dilakukan dengan mencetak tugas.

(Purbo, 2002) menjelaskan e-learning dengan mendefenisikan istilah "e" atau singkatan dari elektronik dalam e-learning digunakan sebagai istilah untuk segala teknologi yang digunakan untuk mendukung usaha-usaha pengajaran lewat teknologi 
elektronik internet. Internet, Intranet, satelit, tape audio/video, TV interaktif dan CDROM adalah sebagian dari media elektronik yang digunakan.

\section{Tahapan Pelaksanaan}

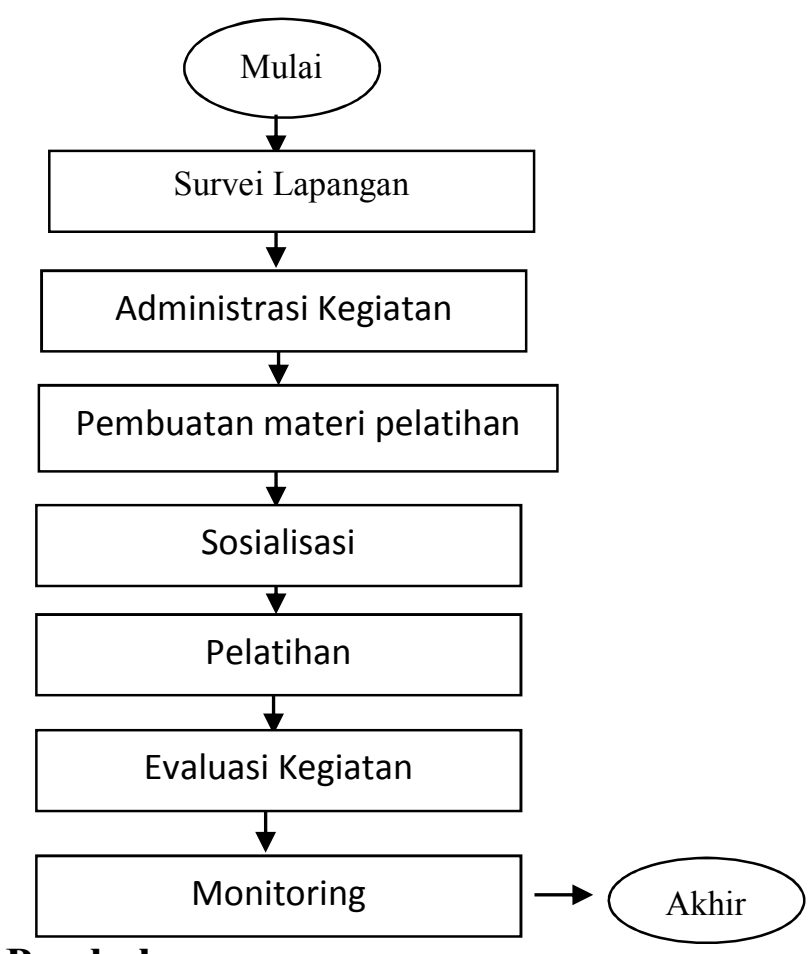

\section{Hasil dan Pembahasan}

Berdasarkan hasil diskusi dan angket awal yang kami lakukan pada SMPIT Taruna Insani (Boarding School) 82\% responden menyatakan belum ada pembelajaran elearning berbasis web dan $100 \%$ responden membutuhkan pembelajaran e-learning berbasis web agar dapat bertukar atau berbagi file yang berhubungan dengan materi sekolah atau kegiatan sekolah, berdiskusi melalui forum diskusi, melakukan ujian atau ulangan harian dan peserta didik melakukan unggah tugas serta pengajar melakukan penilaian langsung melalui e-learning.

Untuk mengatasi permasalahan tersebut, Kami menyarankan dan membuat suatu solusi berupa open education dengan menggunakan fasilitas e-learning. E-Learning (pembelajaran secara elektronik), dengan konsep ini sistem belajar mengajar akan tidak terbatas ruang dan waktu. Seorang pengajar/pengajar dapat memberikan materi pelajaran dari mana saja. Begitu juga seorang peserta didik dapat mengikuti aktifitas pembelajaran dari mana saja. Untuk mendapatkan hasil yang efektif dan efisien, penyelenggaraan pengabdian masyarakat dilakukan secara terstruktur dan materi pelatihan dirumuskan sesuai dengan kebutuhan peserta baik peserta pengajar maupun para peserta didik santri.

Untuk memperkenalkan open education dengan menggunakan fasilitas elearning, kami melakukan sosialiasi terlebih dahulu. Kegiatan sosialisasi dilakukan dengan memberikan pemahaman mengenai konsep e-learning, komponen e-learning, teknologi pendukung e-learning, kelebihan dan kekurangan e-learning serta e-learning sebagai blended system penunjang kegiatan proses belajar mengajar. Langkah selanjutnya kami mempersiapkan materi pelatihan meliputi manajemen user, 
Manajemen Konten, Quiz dan Forum. Setelah materi ajar siap maka kami melakukan pelatihan e-learning bagi pengajar dan peserta didik. Pelatihan untuk pihak pengajar diberikan dalam beberapa tahapan pelatihan yang mulai dilaksanakan setiap hari kamis tanggal 11, 16, 25 Agustus dan 1 September 2016 mulai pukul 9.00 sampai dengan pukul 16.00 WIB.

\section{Tabel 1. Rincian Kegiatan}

\begin{tabular}{|c|c|c|}
\hline No & Tanggal & Kegiatan \\
\hline 1 & 11 Agustus 2016 & $\begin{array}{l}\text { - Pembuatan account keanggotaan open education } \\
\text { - Verifikasi dan validasi oleh pihak administrator } \\
\text { - Manajemen user terdiri dari Pengaturan Profil Pengguna } \\
\text { E-learning (update profile), Mengatur Banyaknya } \\
\text { Pertemuan dalam satu semester (per topik atau per } \\
\text { minggu) dan Enroll User digunakan pengajar untuk } \\
\text { mendaftarkan peserta didik ke dalam sebuah mata } \\
\text { pelajaran yang diajarkan oleh pengajar tersebut agar } \\
\text { peserta didik dapat mengakses materi mata pelajaran yang } \\
\text { dia ambil dan ikut serta dalam pembelajaran menggunakan } \\
\text { e-learning. }\end{array}$ \\
\hline 2 & 16 Agustus 2016 & $\begin{array}{l}\text { - Manajemen Konten terdiri dari pembuatan label, unggah } \\
\text { RPP (Rencana Pelaksanaan Pembelajaran) Menurut } \\
\text { Permendikbud Nomor 65 Tahun } 2013 \text { tentang Standar } \\
\text { Proses RPP yaitu rencana kegiatan pembelajaran tatap } \\
\text { muka untuk satu pertemuan atau } \\
\text { lebih. RPP dikembangkan dari silabus untuk mengarahkan } \\
\text { kegiatan pembelajaran peserta didik dalam upaya } \\
\text { mencapai Kompetensi Dasar. } \\
\text { - Melakukan publish konten bahan ajar dalam bentuk file ( } \\
\text { docx,xls,ppt). } \\
\text { - Memperbaharui (update), memindahkan (drag) dan } \\
\text { menghapus (delete) konten } \\
\text { - Membuat Assigment (upload tugas) } \\
\text { - Memberikan nilai penugasan }\end{array}$ \\
\hline 3 & 25 Agustus 2016 & $\begin{array}{l}\text { Pelatihan quiz dan forum terdiri dari kegiatan: } \\
\text { - Membuat Bank soal, kuis online dapat berupa soal essay } \\
\text { maupun pilihan ganda untuk soal pilihan ganda, pengajar } \\
\text { bisa langsung menetapkan jawaban yang benar beserta } \\
\text { nilainya sehingga peserta didik dapat langsung } \\
\text { mengetahui nilainya. Untuk membuat quiz terlebih } \\
\text { pengajar dahulu membuat bank soal untuk menampung } \\
\text { soal-soal yang akan diberikan kepada peserta didik. } \\
\text { - Membuat soal essay } \\
\text { - Mempublish kuis } \\
\text { - Memberikan nilai untuk quiz essay } \\
\text { - Membuat Forum diskusi, diskusi yang dilakukan oleh } \\
\text { pengajar kepada peserta didik atau diskusi yang dilakukan } \\
\text { oleh peserta didik kepada sesama peserta didik. Untuk } \\
\text { kebutuhan akan pentingnya diskusi elearning }\end{array}$ \\
\hline
\end{tabular}




\begin{tabular}{|c|c|c|}
\hline No & Tanggal & Kegiatan \\
\hline & & menyediakan fasilitas forum didalam setiap coursenya \\
\hline 4 & $\begin{array}{l}\text { 1 September } \\
2016\end{array}$ & $\begin{array}{l}\text { Pelatihan bagi peserta didik } \\
\text { - Pembuatan akun } \\
\text { - Pengambilan materi ajar dengan cara mengunduh } \\
\text { - Melakukan unggah tugas } \\
\text { - Melakukan quiz online } \\
\text { - } \quad \text { Forum diskusi dan chat }\end{array}$ \\
\hline
\end{tabular}

Berikut adalah gambaran suasana pelatihan bagi para pengajar dan peserta didik SMP IT Taruna Insani :
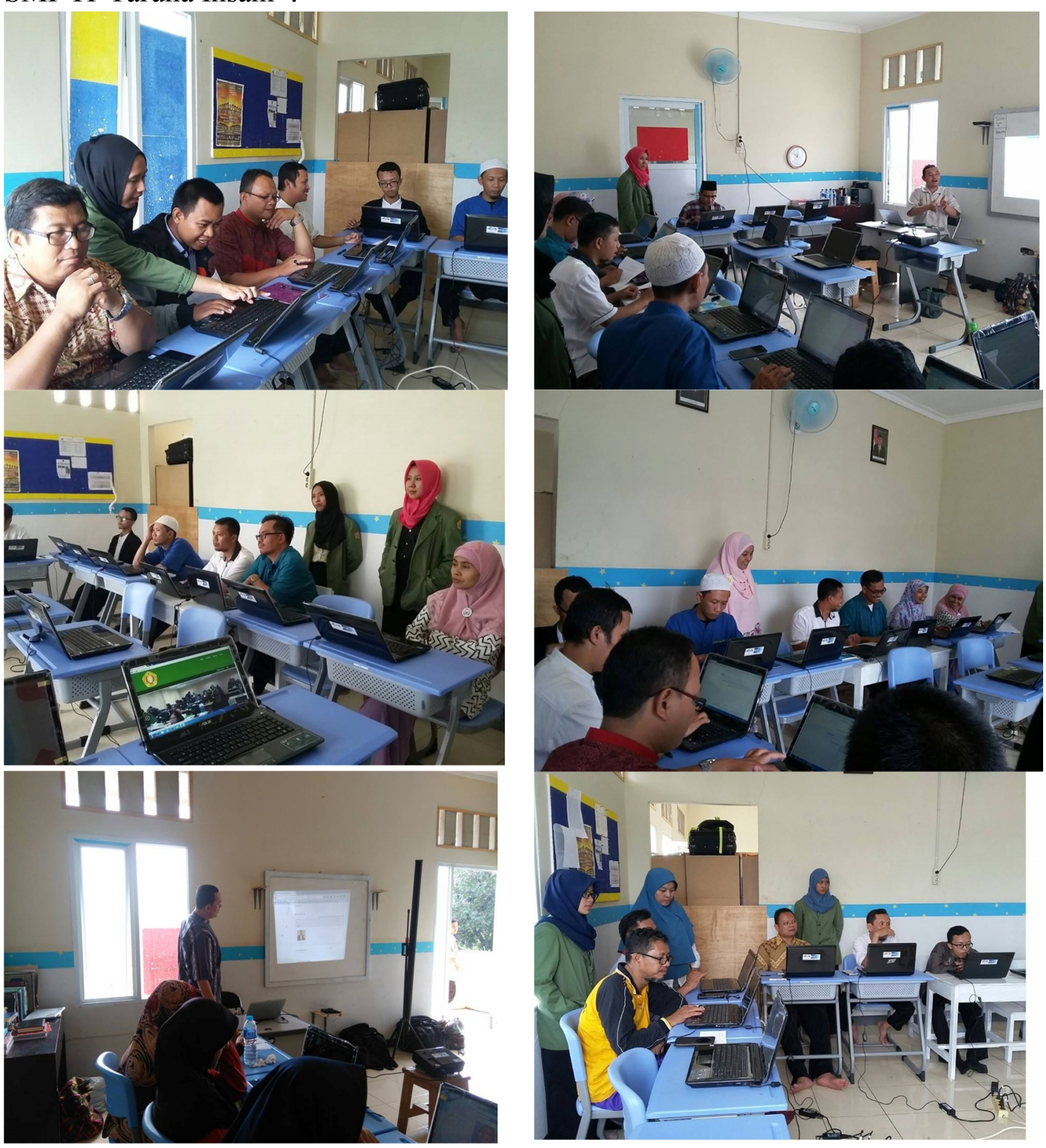

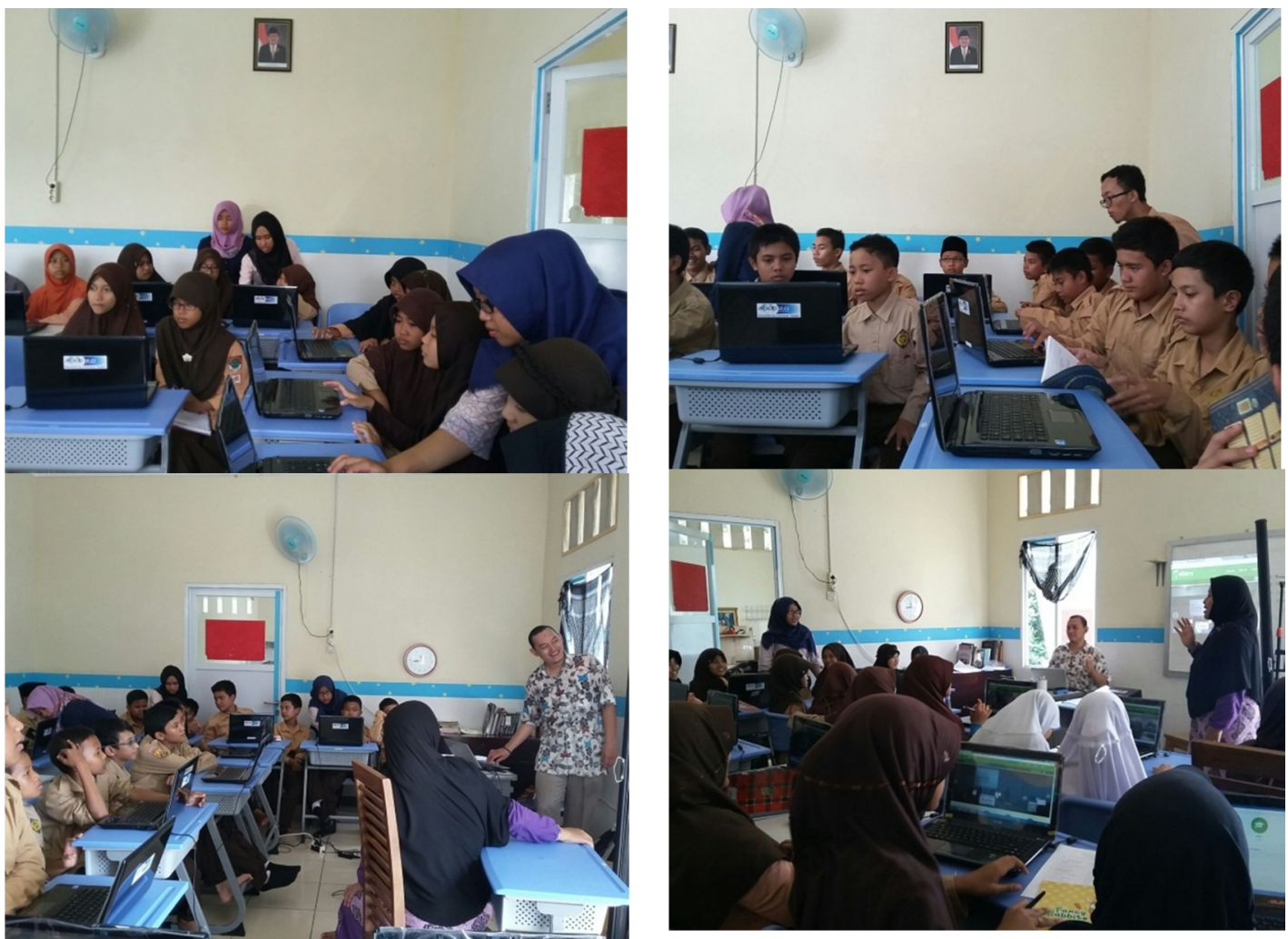

Gambar 1. Suasana Pelatihan
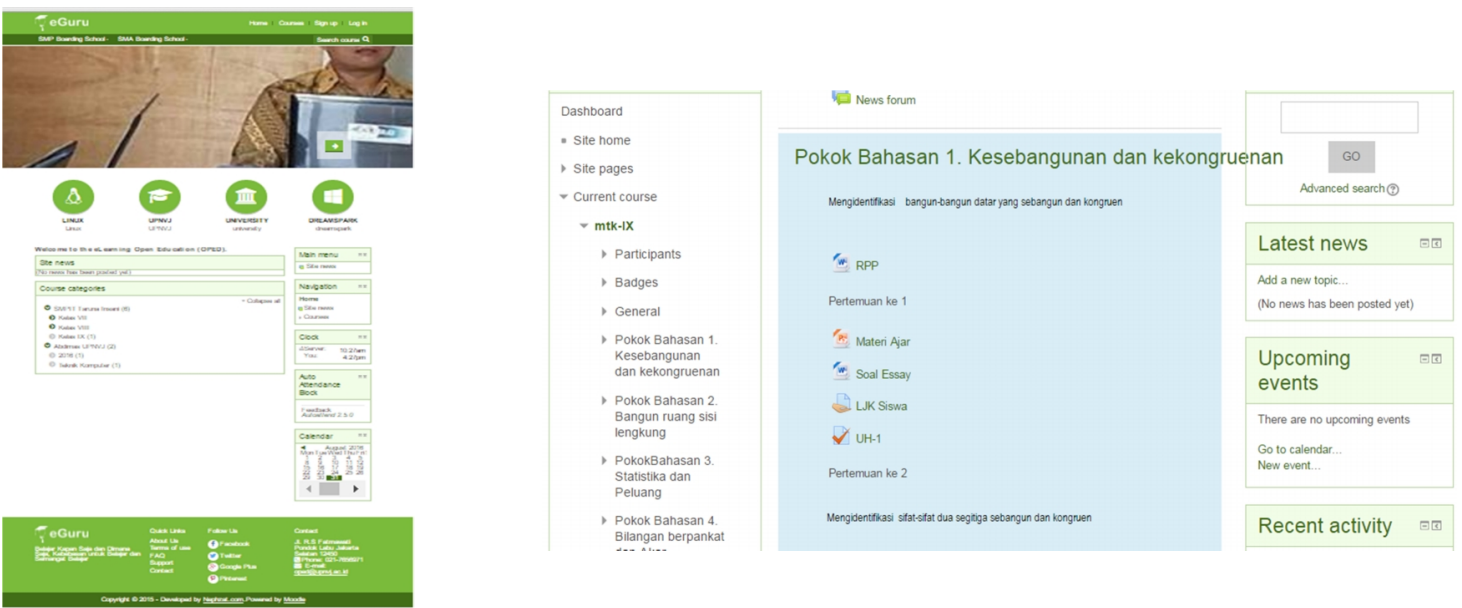

\section{Gambar 2. Tampilan Open Education}

Setelah melakukan pelatihan kami mengevaluasi Kegiatan dan diskusi : Evaluasi diberikan untuk setiap materi pelatihan yang diberikan dengan metode diskusi dan tanya jawab seputar tema pelatihan. Peserta antusias dalam pelaksanaan pelatihan, kami melakukan angket untuk dapat mengevaluasi pelatihan yang kami lakukan terhadap kegiatan pengabdian masyarakat. Respon yang kami terima antara lain : 


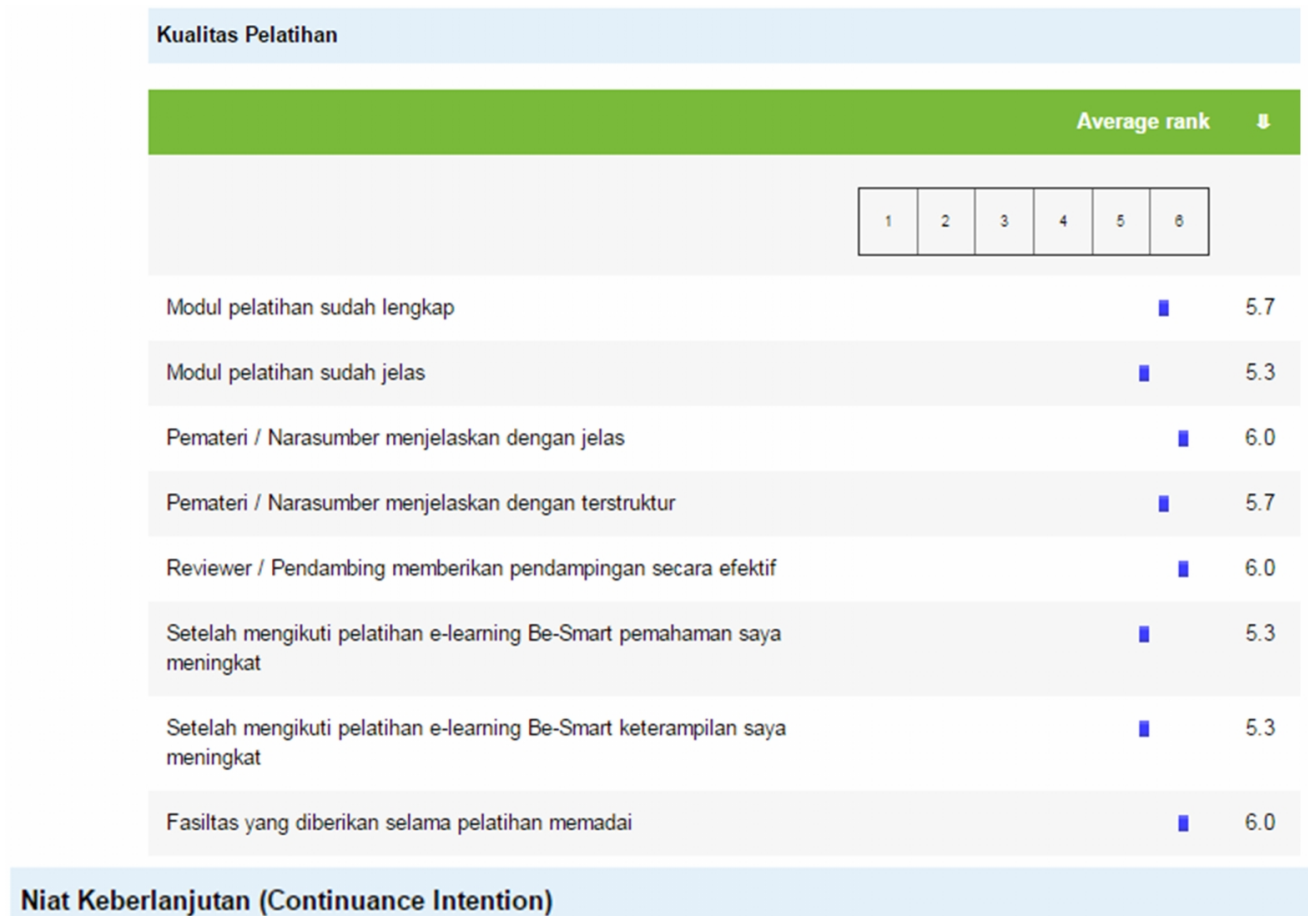

Saya akan menggunakan E-learning untuk membantu saya mengajar di masa depan

\section{Gambar 3. Evaluasi Kegiatan}

Kegiatan pembimbingan dan pendampingan berkelanjutan dapat dilakukan melalui kegiatan diskusi dan pelatihan kembali sampai pihak SMP IT Taruna Insani dapat menggunakan Open education dengan e-learning secara baik dan berkelanjutan. Progressnya akan terus dipantau dan diarahkan. Hal ini bisa dilakukan karena dapat dimonitor oleh pengabdi secara online, kapan saja dan dimana saja.

\section{Kesimpulan}

Pengabdian IbM Penerapan Open Education pada Sekolah Menengah Pertama Islam Terpadu Taruna Insani Boarding School telah dapat dijalankan dengan baik dan tanpa halangan yang berarti. Dengan kerjasama tim pengabdian yang baik dan peran serta aktif dari penyuluh/narasumber dalam kegiatan pengabdian ini maka semuanya telah berjalan sesuai yang diharapkan dan harapannya dapat memberikan manfaat bagi mitra pengabdian masyarakat dalam hal penggunaan open educationdan dapat menunjang proses pembelajaran secara online. Sehingga pada saat para peserta didik 
berlibur untuk kembali ke keluarga masing - masing 1 bulan sekali. Kegiatan belajar mengajar tetap dapat terlaksana dengan baik. Pengabdian yang kami lakukan ini telah sampai pada tahapan pelatihan penggunaan open education bagi para pengajar dan peserta didik meliputi manajemen user, manajemen konten, pelatihan quiz dan forum.

\section{Ucapan Terima Kasih}

Penulis mengucapkan terimakasih kepada Lembaga Penelitian dan Pengabdian Masyarakat (LPPM) UPN "Veteran" Jakarta yang telah membiayai pengabdian masyarakat. Dan Kepada SMP IT Taruna Insani, Sasak Panjang, Bogor yang telah memberikan kesempatan untuk melaksanakan pengabdian ini.

\section{Daftar pustaka}

Ali, M, (2004)E-learning in Indonesian Education System. A paper presented at Seminar-Workshop on E-learning : The Seventh Programming Cycle of APEID Activities, 30 August-6 September 2004 in Tokyo and Kyoto, Japan

Bates, A. W. (1995)Technology, Open Learning and Distance Education. London: Routledge

Brown, Mary Daniels. Education World: Technology in the Classroom: Virtual High Schools, Part 1, The Voices of Experience. http://www.educationworld.com/a_tech/tech052.shtml ( 16 April 2016).

Koswara, E. (2005)Konsep Pendidikan Tinggi Berbasis E-learning : Peluang dan Tantangan. Prosiding Konferensi Nasional Teknologi Informasi dan Komunikasi Indonesia ITB, 3-4 Mei 2005

Natakusumah, (2002)E.K. Multimedia sebagai sarana pembelajaran; Lokakayra Multimedia sebagai sarana pembelajaran metode learning based; DUE-Like TPB ITB, 13 Nopember 2002.

Natakusumah, E.K.(2002) Teknologi informasi pada pendidikan jarak jauh, Orasi Ilmiah pada Wisuda STMIK Bandung, 12 Januari 2002, Grand Aquila Hotel, Nusantara Ball Room, Bandung.

Newsletter of Open and Distance Learning Quality Council, October 2001. http://www.odlqc.org.uk/odlqc/n19-e.html (16 September 2002)

Purbo, Onno W. dan Antonius AH. (2002). Teknologi e-Learning Berbasis PHP dan MySQL: Merencanakan dan Mengimplementasikan Sistem e-Learning. Jakarta: Gramedia.

Siahaan, S. (2004) E-learning (Pembelajaran Elektronik) Sebagai Salah Satu Alternatif Pembelajaran http://www.depdiknas.go.id/Jurnal/42/ sudirman.htm (3 November 2006) 